\title{
Graphics for Horticulture Students
}

\author{
Pauline Hurley-Kurtz
}

AdDITIONAL INDEX WORDS. art, creativity, drawing, sketch, communication

Summary. This paper discusses the benefits of including the visual and graphic arts in a horticultural curriculum, as a means for fostering creativity and reading the landscape. It describes the curricular sequence in the graphic communication seminar and studio-a joint studio for horticulture and landscape architecture students at Temple University, Ambler, Pa. This sequence begins with freehand drawing, and progresses to mechanical drafting, drawing construction and rendering.

$\mathrm{T}$ he Department of Landscape Architecture and Horticulture at Temple University, Ambler, Pa., offers BS and AS degrees in Horticulture and a BS in Landscape Architecture. One of the fundamental strengths of our programs is a strong, common, core curriculum that includes graphics and design studios for horticulture students and classes in woody and herbaceous plants for landscape architecture students. All classes and studio projects support an overarching departmental philosophy of an ecological, sustainable approach to the planning, design and maintenance of the land.

Traditionally, graphics and design are unusual components of a science-based horticultural curriculum. However, these elements historically have been a component of the horti-

Associate professor, Department of Landscape Architecture and Horticulture, Temple University, 580 Meetinghouse Rd., Ambler, PA 19006-3994.

Since 1996, a number of instructors have contributed to the development of the Graphic communication studio and deserve recognition. They are E. Anderson, M. Bowe, and J. Meschter. Also, thanks to G. Whiting B. Lamba, and L. Blum for reviewing this paper in it's early stages. Special thanks to R. Lyons and D. Hensley for their thorough editing. The cost of publishing this paper was defrayed in part by the payment of page charges. Under postal regulations, this paper therefore must be hereby marked advertisement solely to indicate this fact. 
culture program at Temple University's Ambler campus since its inception as the Pennsylvania Women's School of Horticulture in 1910. Also, studios provide a common ground for students in both disciplines to work together, often fostering partnerships that continue into professional careers. Facility with drawing and design is a tool for the expression of creative ideas irrespective of discipline, and creative thinking is fundamental to good science.

\section{Art as a catalyst for creativity}

A horticulture student trained in art and design will use powers of visualization, and a right brain creative process (Edwards, 1979) to become a more creative thinker and therefore a more successful horticultural scientist. Janick (1972) states that "Horticulture is an ancient art, and many of its practices have been empirically derived. However, modern horticulture, as agriculture, has become intimately associated with science, which has served not only to provide the methods and resources to explain the art, but has become the guiding force for it's improvement and refinement. Horticulture will never become wholly a science, nor is this particularly desirable. Its curious mixture of science (botany to physics), technology, and esthetics makes horticulture a refreshing discipline that has continually absorbed man's interest and challenged his ingenuity. The science of horticulture nevertheless remains the dynamic influence in the proper use and understanding of the horticultural art." Thus, science provides a framework for understanding the art of horticulture, and is a means for its improvement.

In a more holistic time when boundaries between disciplines were less well defined, the descriptive arts and science were integrated in the pursuit of creativity. Renaissance artist Leonardo da Vinci's scientific sketches ranged from anatomy and geology to applied mechanics (Wallace, 1966). American colonial botanist, William Bartram, illustrated his travels with

Fig. 1. (A) A pure contour line drawing of prince's-feather (Amarantbus bybridus $\mathbf{L}$. var. erytbrostachys Moq.) drawn without reference to the page (by J. Rosencrance in 1999). (B) A modified contour line drawing of a pepper plant (Capsicum $\mathrm{L}$.) where the emphasis was on drawing the edge of the object (by P.R. Ruch in 1996). botanical sketches of the species found during explorations of Florida and the southern United States (Bartram, 1791). Watson and Crick acknowledge the contribution of inspiration, visualization and iteration in the discovery of the structure of DNA (Watson, 1968). Certainly, science requires creative thinkers to make and understand extraordinary discoveries.

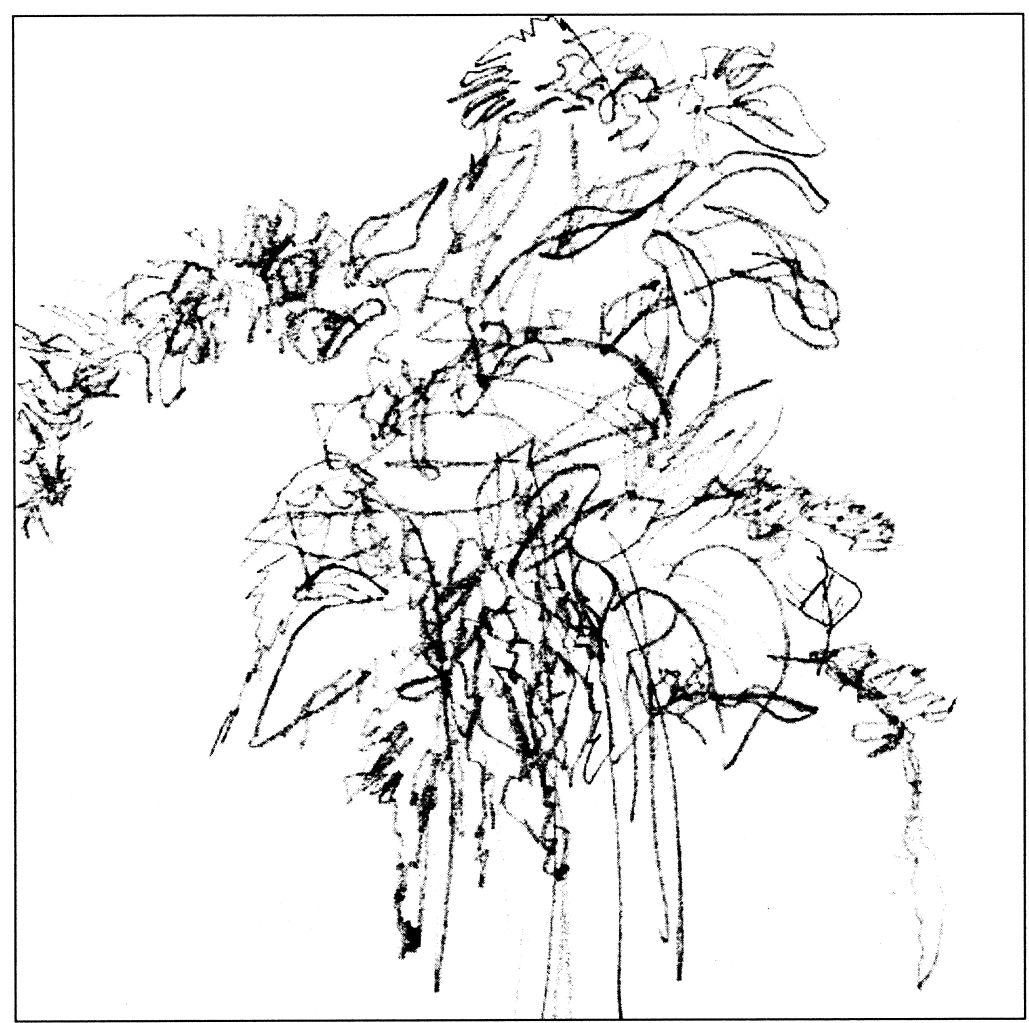

Fig. 1A

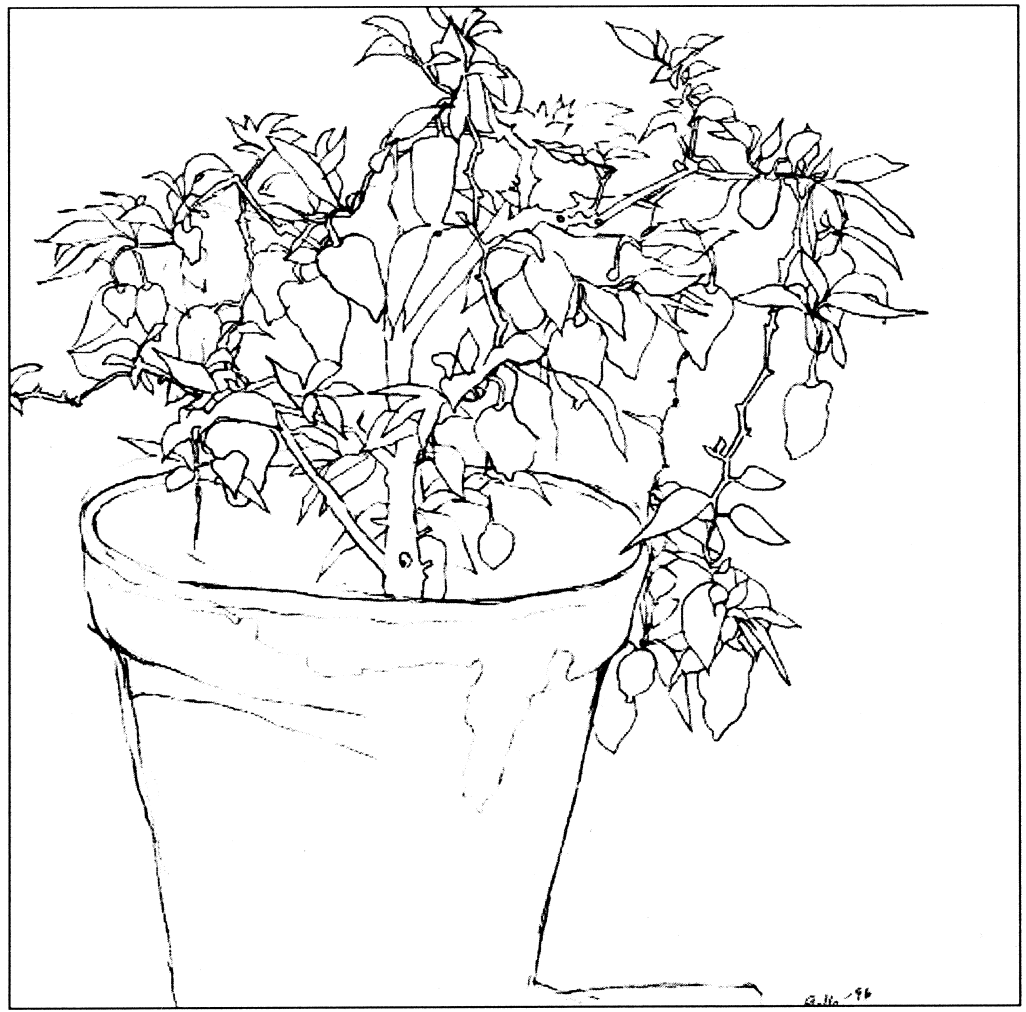

Fig. 1B 


\section{Reading the landscape}

Students in the horticulture and landscape architecture programs participate in the design, maintenance, and restoration of the Ambler campus gardens and landscapes. As one gen- eration designs, plants and cares for a garden, the next studies these spaces as subjects for drawing. Through drawing one can understand a landscape's intrinsic character or sense of place. Motloch (1991) defines sense of place as "All things viewed within a space,

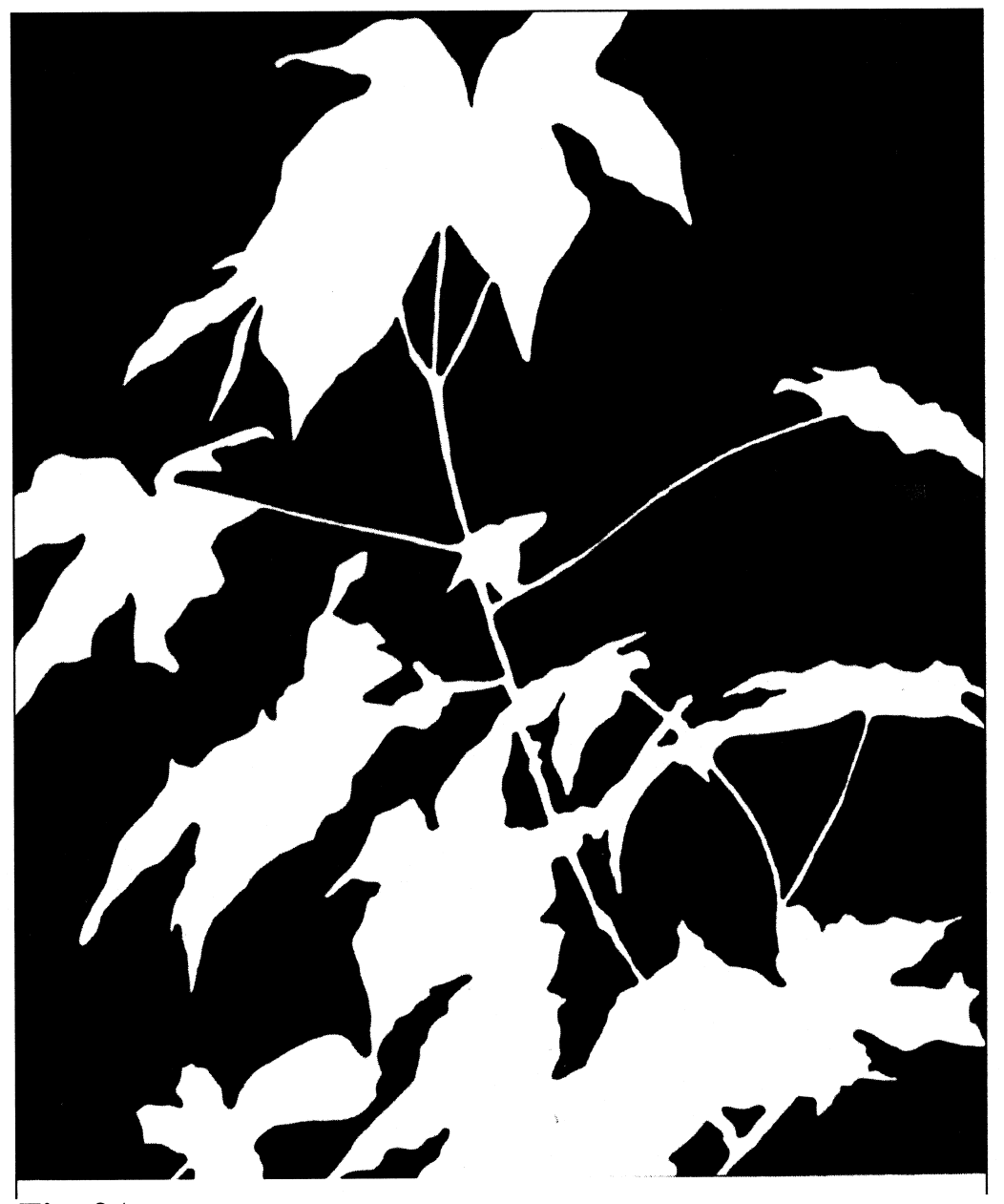

Fig. 2A

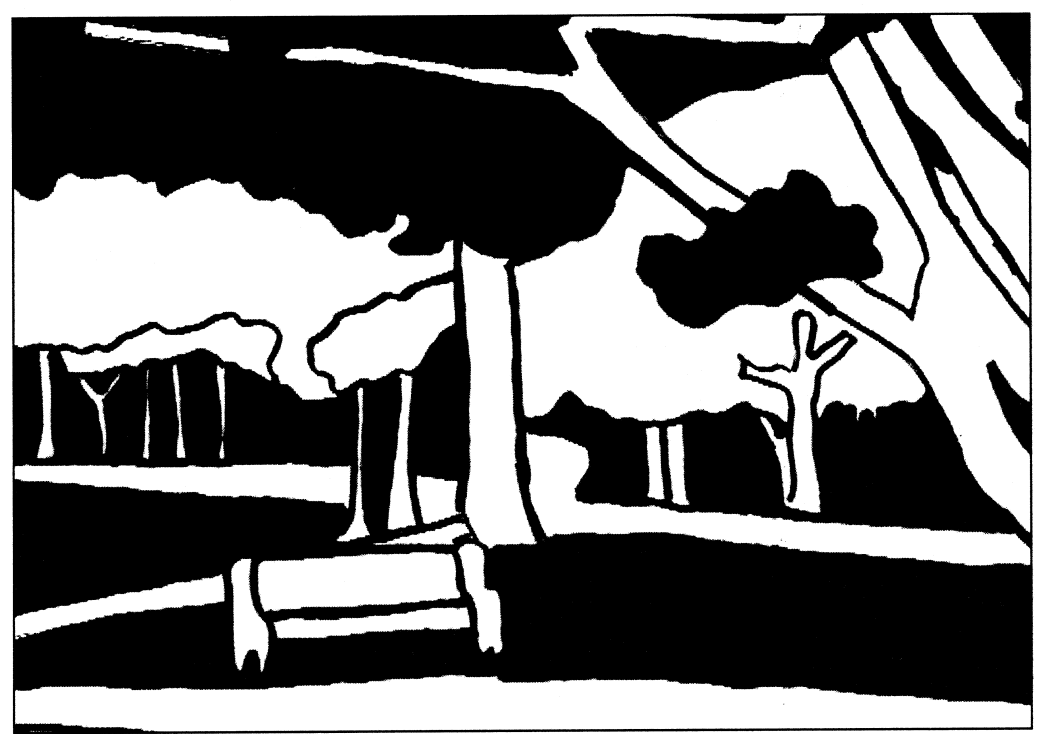

Fig. 2B

including the base plane, overhead plane, spatial edge, enclosed elements, and enframed ones are part of the visual scene, and therefore part of the place. If the various stimuli relate to one another and support a common theme, then the space has a strong meaningful sense of place. It feels integrated; its elements feel like they belong together. The space can be said to have a high degree of placeness."

\section{Graphics curriculum structure}

The graphics courses (LA 101, LA 103) for horticulture students occur in the fall semester of their second year and are taken jointly with landscape architecture students. The graphic communication sequence includes a one credit seminar with a three credit studio. The seminar introduces concepts and theory of the current studio topic. Studios are limited to 15 students, and currently four separate sections are taught. A range of traditional graphics tools and media are used in studio. These include soft graphite, charcoal and mechanical pencils, inks and watercolor wash. Students use a variety of paper including newsprint, drawing paper, yellow trace, vellum and mylar. Digital tools QuarkXPress Passport (Quark Inc., Denver, Colo.) for desktop publishing and Photoshop (Adobe Systems Inc., San Jose, Calif.) for image manipulation are also introduced over the course of the semester.

The studio is designed as a series of cumulative drawing exercises. The first half of the semester focuses on freehand drawing, two dimensional drafting and lettering. Students also work on a parallel research exercise for the seminar class addressing a particular artist's drawing technique. A field trip to the Philadelphia Art Museum broadens their understanding of landscape drawing and painting. An informal midsemester review is a forum for displaying the work of different studio sections. Students learn from the work of their peers, and again this provides an opportunity for discussion.

Fig. 2. (A) A negative space drawing of a sweetgum (Liquidambar styraciflua L.) seedling, where the focus was on drawing the spaces between the object and the format (by C. Scorsone in 1997). (B) A freehand landscape perspective by Durer's method with negative space emphasized (by A.M. Dower in 1998). 
The second half of the semester concentrates on three dimensional drawing, rendering, and verbal presentation techniques. Students also maintain a journal of visual and written notes which is called The Ambler Notebook. The semester concludes with formal student presentations to a jury of invited guests. Jurors generally are faculty members, with professional horticulturists and landscape architects from the Philadelphia area.

\section{Graphic communication sequence-Freehand drawing}

Throughout the graphic communication studio, emphasis is placed on learning to draw by learning to see as an artist. The first exercises introduce the concept that drawing is a learnable skill (Edwards, 1979), if one allows the activation of the right brain hemisphere- the locus for creativity. This is an important reinforcement for both horticulture and landscape architecture students, many of whom have limited or nodrawing experience. Essentially, these exercises trick the analytical, logical left brain into a secondary role, allowing the creative intuitive right brain to guide the drawing process.

\section{Contour line}

Initial pencil studies develop visual acuity and the artist's ability to see. Exercises focus on drawing the contour line or edge of the subject. Students begin with the pure contour technique, where they observe the subject intently and draw without looking at the page. This is a useful approach for beginning students (Fig. lA). Subsequent exercises based on the modified contour drawing technique, allow some reference to the page as one draws. However, emphasis is placed on concentrated observation and eyehand coordination. Subjects for these exercises are individual plants, shrubs, and trees of the Ambler campus gardens (Fig. 1B).

Contour drawing is then applied to a more complicated landscape vista including masses of vegetation and distinct layers. This may be a view of a perennial garden, or a successional landscape incorporating a meadow,

Fig. 3. A sketch from a grey tone photograph using stippled tone to build light and shadow (by J. Rosencrance in 1999). old field, or woodland sequence. The use of a variety of line weights is emphasized, giving the illusion of perspective.

\section{Negative space}

The concept of drawing a subject is introduced in several exercises by focusing on the rendition of its negative space context. Students see the negative space by observing the subject through a small cardboard frame. The outline of that negative space is drawn and rendered in black, thus revealing the subject's form (Fig. 2A).

An exercise that combines contour, negative space, and perspective principles follows. A sheet of mylar is placed on a window and the scene one observes is drawn by contour line in perspective after Durer's method (Edwards, 1979). The perspective is then enhanced by choosing appropriate layers of the landscape to convert to negative space (Fig. 2B).

\section{Tone and texture}

In preliminary exercises, students learn to create light, shade, and shadow by constructing tone and texture using line, dots, and other shorthand strokes or marks. This technique is then applied to a gray tone photograph. A mark is chosen, and applied in varying densities reflecting the observed grays (Shen and Walker, 1992). Students gain confidence through using this technique (Fig. 3), and subsequently apply this method to freehand drawing and perspective rendering.

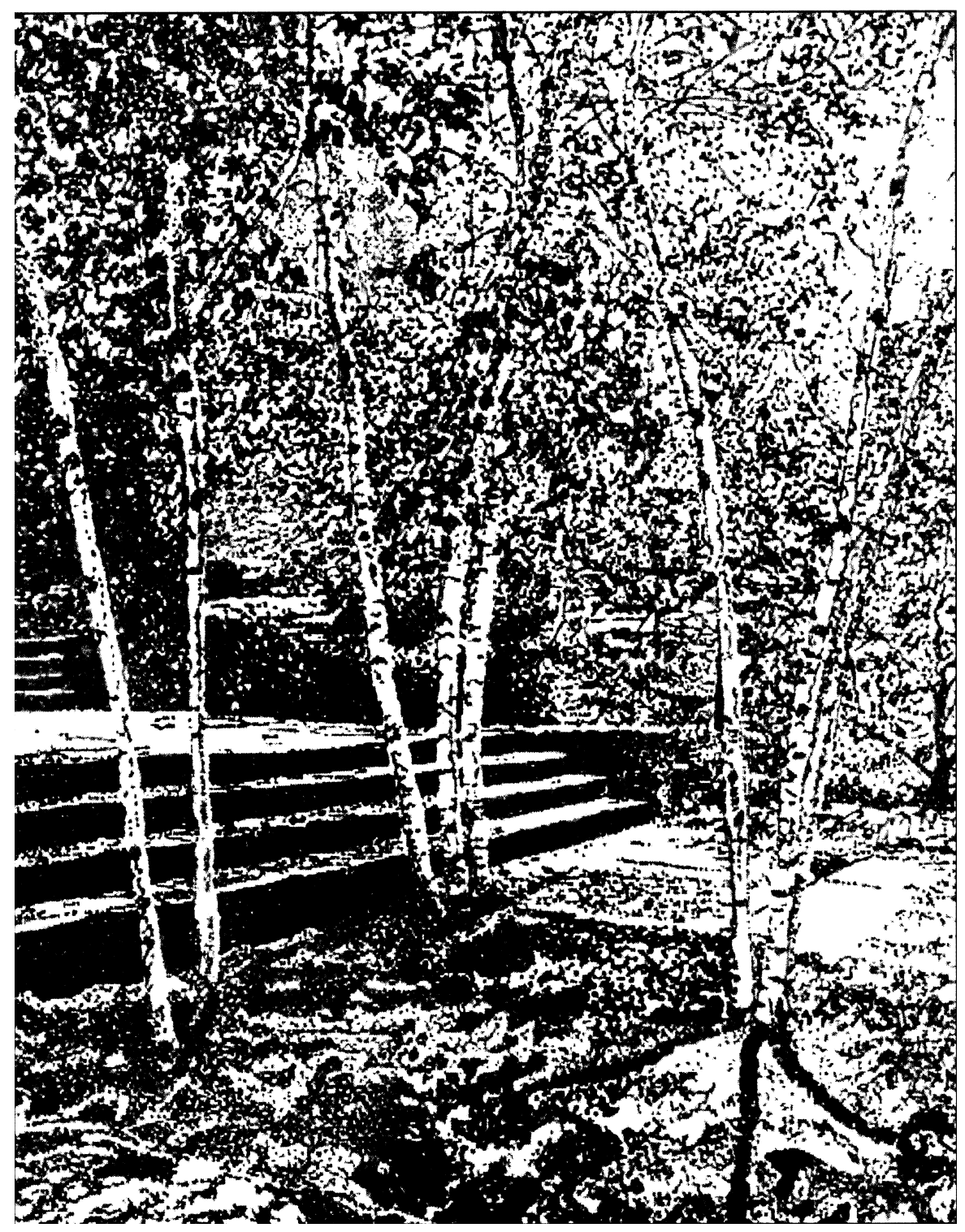




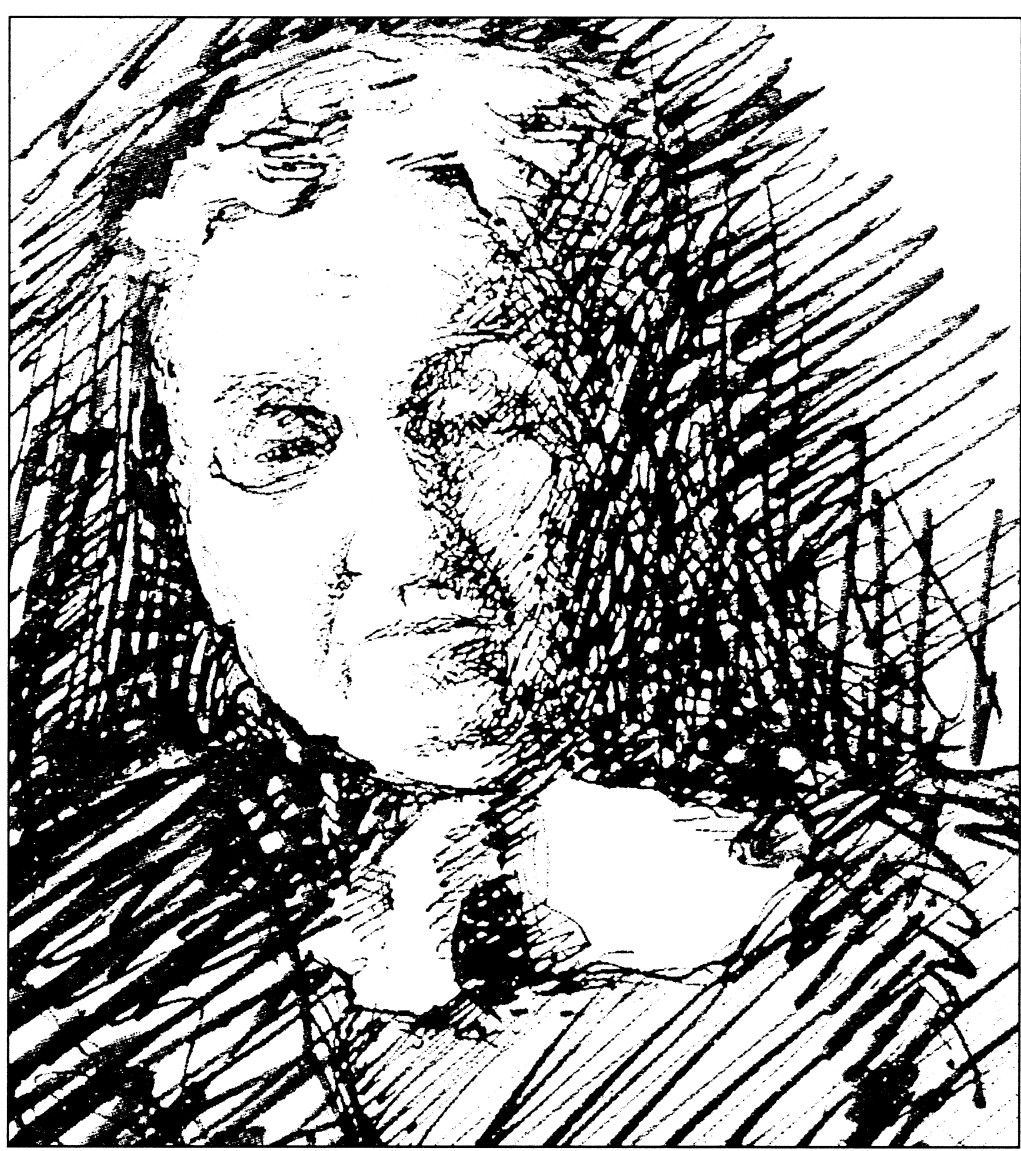

Fig. 4A

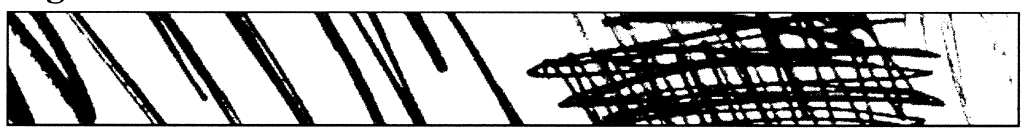

Fig. 4B

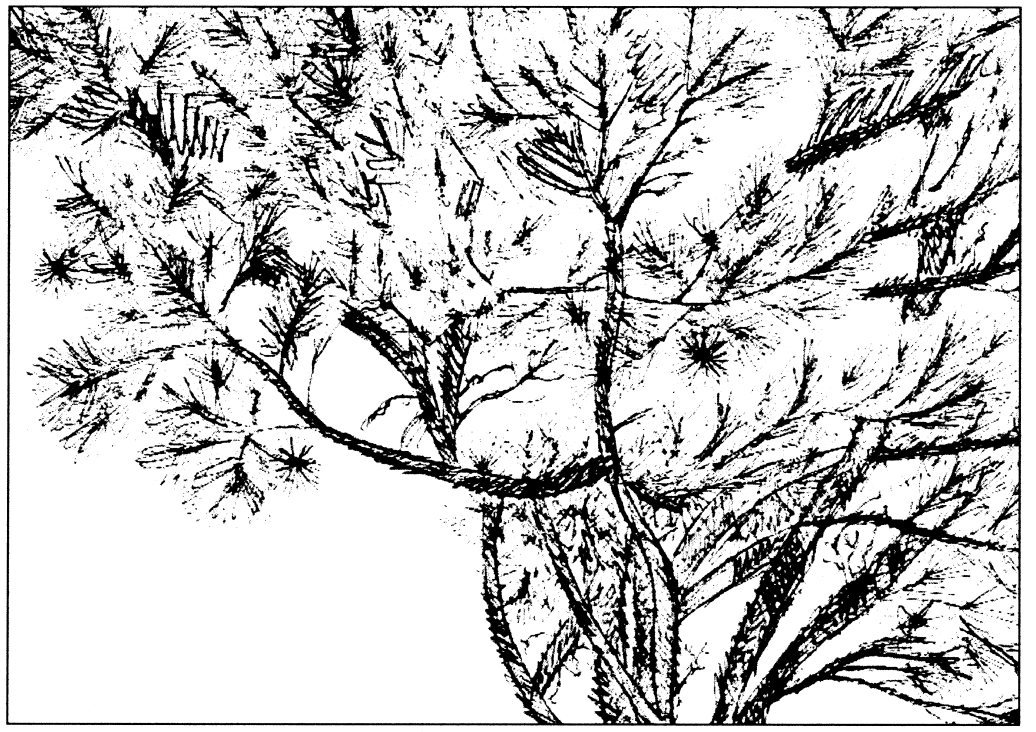

Fig. 4C

Fig. 4. (A) A sketch after Georgia O'Keefe (by L.R. Hart in 1998). (B) Marks or graphic elements identified in Fig. 4A (by L.R. Hart in 1998). (C) Marks or graphic elements used in drawing a pitch pine (Pinus rigida Mill.) tree on the Ambler campus of Temple University, Ambler, Pa. (by L.R. Hart in 1998). (D) Marks or graphic elements used in drawing a pitch pine tree detail (by L.R. Hart in 1998).

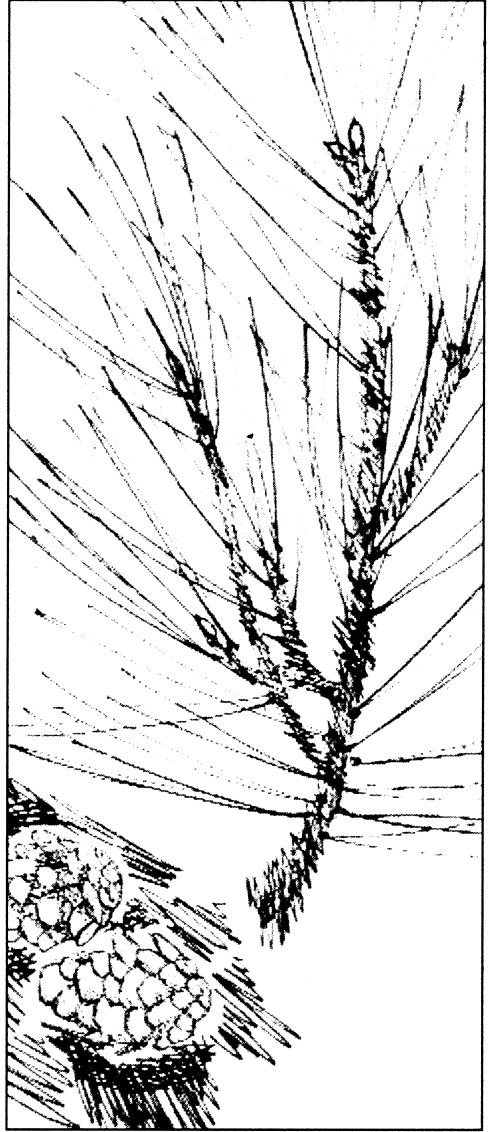

Fig. 4D

Graphic communication seminar

DRAWING INVESTIGATION-MARKS STUDY.

This is a study that reinforces the tone and texture approach to drawing through the analysis of the work of a range of artists and designers. Students study the drawings of their chosen artists (Fig. 4A), in particular the formation and character of particular pen or pencil strokes or marks by which they draw (Fig. 4B). They then apply similar marks to the drawing of a tree of their choice on campus (Fig. 4C), and a tree detail (Fig. 4D). This study is subsequently developed to a digitally generated poster using Photoshop for image manipulation and QuarkXPress Passport for layout and desktop publishing,

A field trip to the Philadelphia Art Museum illustrates the enormous variety of techniques used for landscape drawing and painting in different cultures and over time. The work of artists who had particular influence on landscape design is emphasized. Students observe and draw from the sculptures and paintings in the galleries (Fig. 5).

Students maintain a journal of visual and written notes from seminar, 


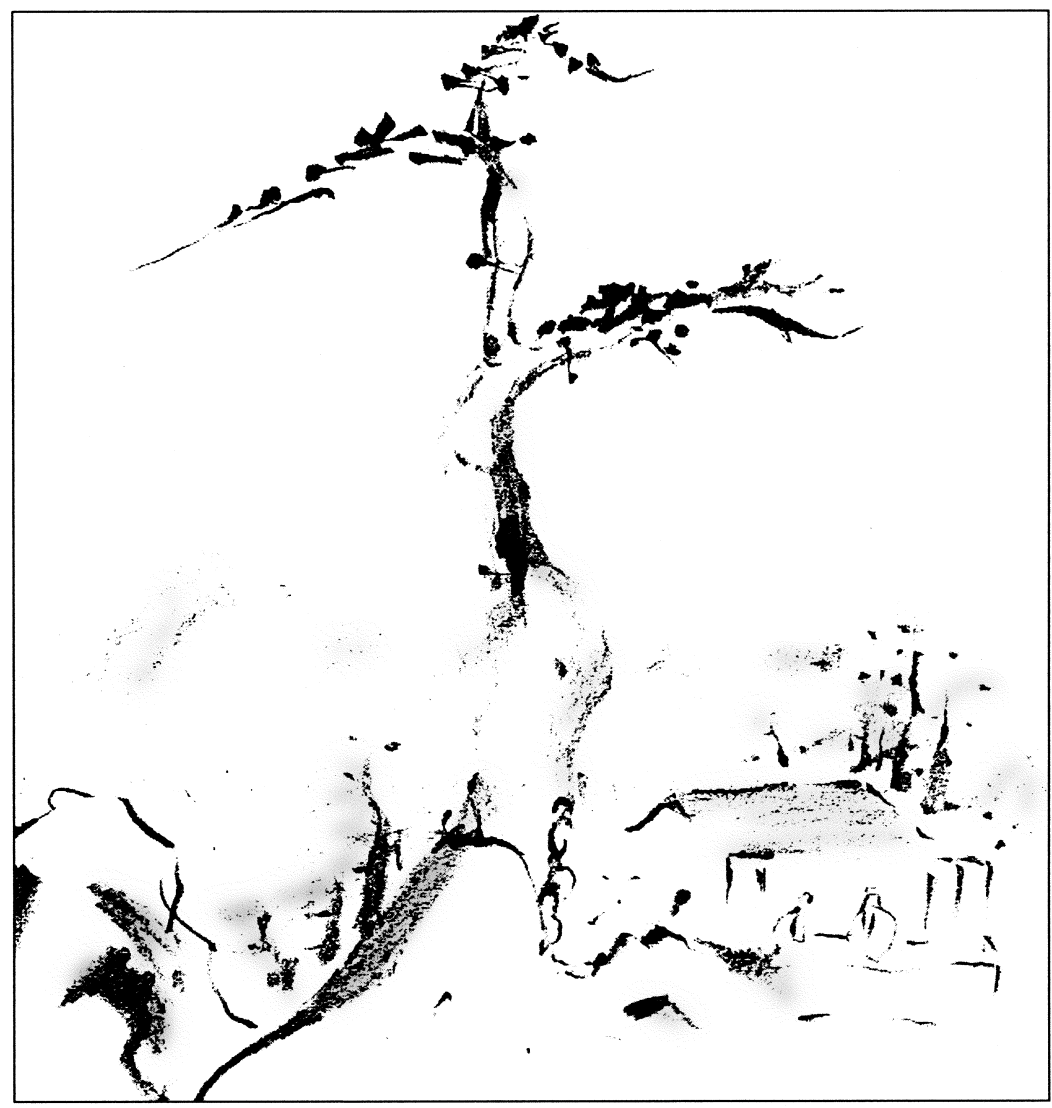

Fig. 5. Enjoying the moon in a riverside cottage after Ike no Taiga. (by P.R. Ruch in 1996). Philadelphia Art Museum.

studio, guest lecturers and homework assignments throughout the semester. This practice of making visual notes is the habit of good designers and artists (Fig. 6).

Graphic communication seQuence-
MEASURED DRAWING: TWO DIMENSIONS. Principles learned in freehand drawing are combined along with graphic conventions, symbols, and appropriate scale in measured drawing techniques. Students measure and sketch campus gar-

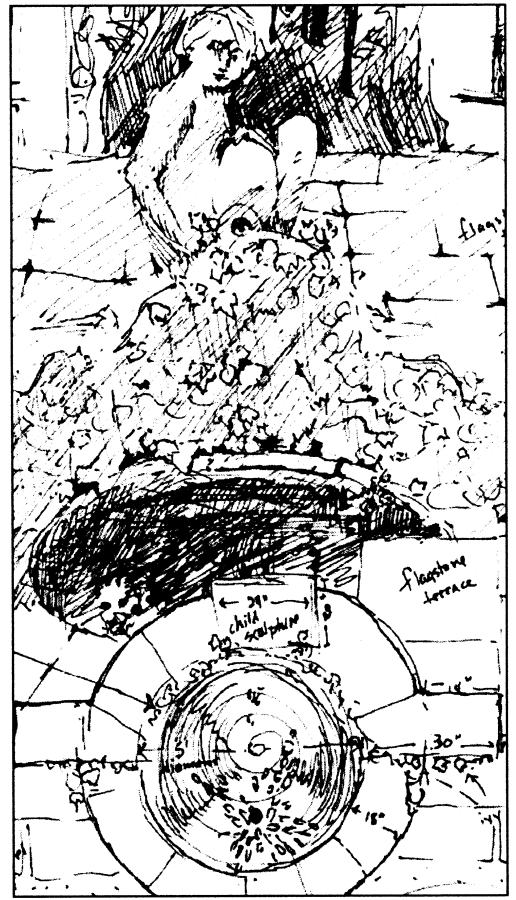

Fig. 6. A sketch of the Bright Memorial fountain, Ambler campus, Temple University, Ambler, Pa. (by P.R. Ruch in 1996).

den spaces before drawing them in two dimensions as a plan, diagram and section. A diagram exercise introduces the language and symbols of landscape site analysis (Fig. 7A). Campus gardens are studied in terms of circulation, space, edge, node and focal point. This drawing is either hardline or freehand in ink. A legend and title block are required.

Fig. 7. (A) A diagram describing space, circulation, nodes, views and focal points in the Ambler campus perennial garden, Temple University, Ambler, Pa. (by J. Rosencrance in 1999). (B) A plan of Dixon Hall terrace, Ambler campus, Temple University, Ambler, Pa. (by T.T. Claghorn in 1999). (C) A section and elevation of the Ambler campus entrance, Temple University, Ambler, Pa. (by J. Rosencrance in 1999).

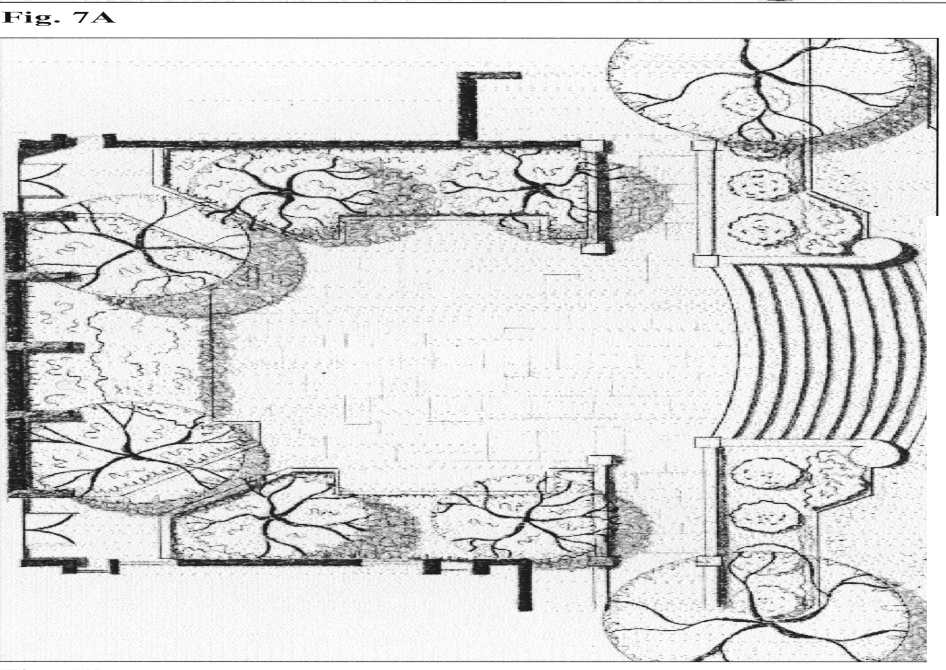

Fig. $7 \mathrm{~B}$

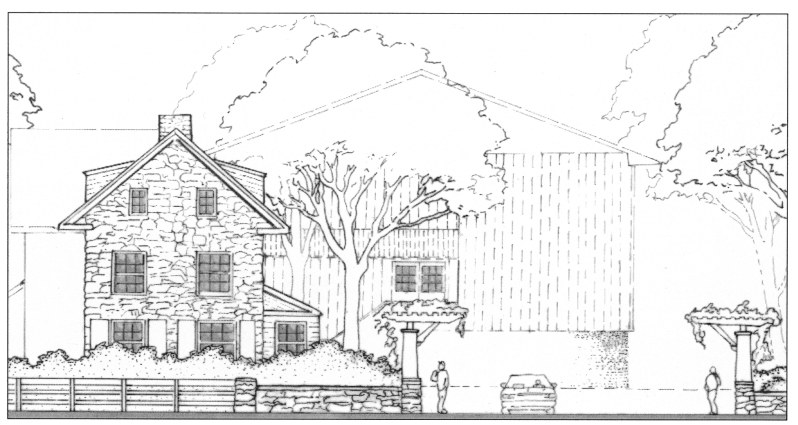

Fig. 7C 


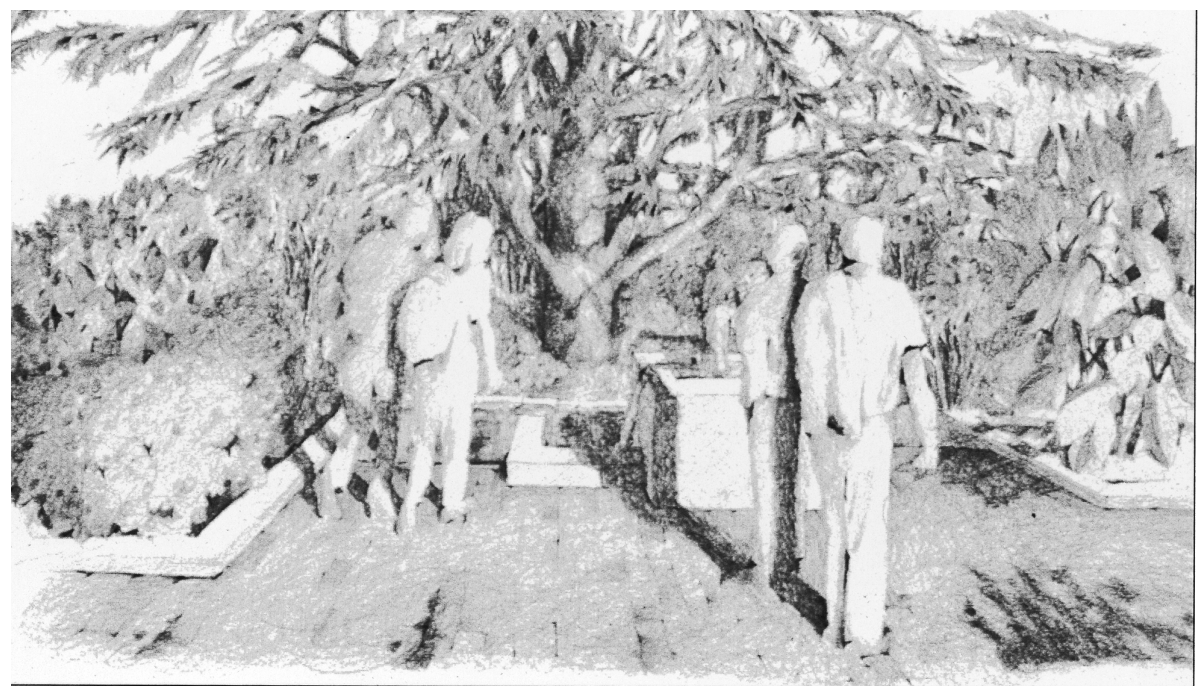

Fig. 8A
Fig. 8. (A)A one-point perspective drawing of Cottage Hall fountain on Temple University's Ambler campus, Ambler, Pa. (by P.R. Ruch in 1996). (B) A three-dimensional axonometric drawing of Cottage Hall courtyard on Temple University's Ambler campus, Ambler, Pa. (by P.R. Ruch in 1996). (C) A two-point perspective of Cottage Hall fountain on Temple University's Ambler campus, Ambler, Pa. (by T.T. Claghorn in 1999).

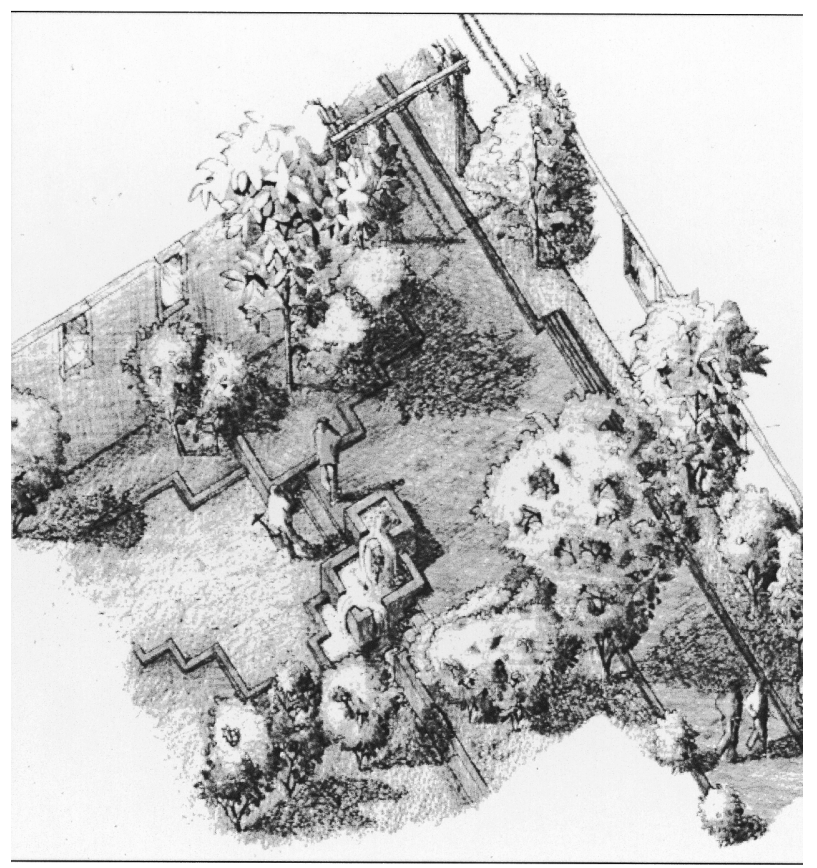

Fig. 8B

The next project is the development of a clear readable plan in pencil. Emphasis is given to line weights and drawing conventions of building and landscape elements. Alternative rendering styles for plant material and hardscape elements are encouraged. Shade, shadow and varying textures add a three dimensional quality to the drawing. Block lettering principles are also introduced (Fig. 7B).

The final two dimensional drawing exercise introduces the mechanics of developing a section drawing from a plan view. Emphasis is on buildings, plant character, material texture, scale figure, measuring line, and lettering.
The final ink or pencil rendering focuses on line weights, and drawing plants with appropriate marks to convey their habit and leaf pattern (Fig.7C).

Graphic communication seQUENCE-MEASURED DRAWING: THREE DIMENSIONS. The second half of the semester concentrates on the development and rendering of three dimensional drawings, the principles and application of color, verbal presentation techniques, and design of illustrated digital documents. The appropriate use of three dimensional drawings, such as one and two point perspectives and axonometric are discussed as a means to illustrate a landscape design. Acampus garden space is drawn as a measured one-point perspective, using the plan projection or grid method. Appropriate use and mechanics of this type of perspective is discussed for the illustration of long narrow spaces (Fig. 8A).

Axonometric is a three dimensional drawing drawn to scale. It is constructed directly from a plan, along the $\mathrm{x}, \mathrm{y}$, and $\mathrm{z}$ axes. Emphasis is placed on using a number of line weights as in prior drawings. The rendering of plants and landscape elements in axonometric are incorporated using shade and shadowstudies. Axonometrics are efficient to construct, and give a prospective client a convincing three dimensional view of a proposed landscape design (Fig. 8B).

A structural element in a campus garden (a fountain, pergola or trellis) is used as a two-point perspective exercise 
using the plan projection or grid method. Again, particular attention is paid to pencil line weights, textures, light, shade and shadow. The development of strong foreground, mid-ground and background zones in the drawing is emphasized (Fig. 8C).

\section{Discussion}

Student reaction to the course is very positive, evidenced by consistently high course evaluations with an average rating of 4.5 out of 5 spanning a 6year period. Student comments recently included some recommendations to allow more time for the more challenging three dimensional drawings at the end of the semester, and we will endeavor to accommodate that request. Through the course of the semester, students develop an ease and facility with drawing. They acquire useful skills, of special interest to those interested in working as landscape designers. Finally, through interaction in studio with fellow students in landscape architecture, one creates an opportunity for discussion that also provides a foundation for future professional collaboration.

\section{Literature Cited}

Bartram, W. 1791. Travels with William Bartram. James and Johnson, Philadelphia.

Edwards, B. 1979. Drawing on the right side of the brain. J.P. Tarcher Inc., Los Angeles.

Janick, J. 1972. Horticultural science. W.H. Freeman, San Francisco.

Motloch, J. 1991. Introduction to landscape design. John Wiley, New York.

Shen, J. and T.D. Walker. 1992. Sketching and rendering for design presentations. Van Nostrand Reinhold, New York.

Wallace, R. 1966. The world of Leonardo 1452-1519. Time Inc., New York.

Watson, J.D. 1968. The double helix. Atheneum, New York. 